\title{
Performance Evaluation of Retail Enterprises Based on Principal Component Analysis
}

\author{
Wenwen Wang \\ Jinan University, Guangzhou, China \\ Email: qiuyeyu2021@126.com
}

How to cite this paper: Wang, W. W. (2021). Performance Evaluation of Retail Enterprises Based on Principal Component Analysis. Modern Economy, 12, 293-302. https://doi.org/10.4236/me.2021.122015

Received: January 6, 2021

Accepted: February 16, 2021

Published: February 19, 2021

Copyright $\odot 2021$ by author(s) and Scientific Research Publishing Inc. This work is licensed under the Creative Commons Attribution International License (CC BY 4.0).

http://creativecommons.org/licenses/by/4.0/

\section{(c) (i) Open Access}

\begin{abstract}
This paper uses factor analysis and principal component analysis to evaluate the performance of 44 retail enterprises. The research found that the profitability and solvency of enterprises are low. The efficiency of asset operation is high and the difference between enterprises is small. Enterprises carry out chain operation, through the allocation of resources in key areas, to establish regional competitive advantage. Department store is the main form of business, and the combination of old and new forms of business has become the mainstream. Therefore, some suggestions are put forward to strengthen the supply chain management and improve the product differentiation degree.
\end{abstract}

\section{Keywords}

Principal Component Analysis, Product Homogenization, E-Commerce, Performance Evaluation

With the development of new retail formats and e-commerce, as well as the increase of labor costs and housing prices, retail enterprises are facing a fierce competitive environment. Therefore, this paper uses factor analysis and principal component analysis to evaluate the performance of 44 listed retail enterprises from 2016 to 2018 .

\section{Literature Review}

\subsection{Literature Review of Performance Evaluation}

In 1911, C. Harrison evaluated performance from the cost dimension. For the first time, DuPont uses the Du Pont System to take the return on equity as the core index, which is not only conducive to the comparison between enterprises, but also conducive to finding the factors affecting performance. Alexander Wole 
proposed the specific gravity score in 1928. In the 1930s, James McKinsey put forward the theory of periodic evaluation. From macro to micro, enterprises determine their own status according to the environment they are facing, and study the factors that enterprises need to pay attention to. In the early 1990s, Kaplan and Norton (1992) used the Balanced Scorecard to evaluate the performance of enterprises. The balanced scorecard includes both quantitative and qualitative indicators. Stern Stewart uses economic value added (EVA) as a measure of corporate performance, which is in line with the business goal of the maximum of Shareholders Wealth. In the 1990s, the theory of human capital strategic management was put forward, which was the first time that human capital was brought into the enterprise performance evaluation system.

\subsection{Literature Review of Retail Industry}

Liao (2007) used principal component analysis to evaluate the performance of 51 listed retail enterprises, and explored the impact of governance structure on enterprise performance. This paper puts forward some measures, such as strengthening $M \&$ developing modern department stores and strengthening the incentive to senior executives. Chen, Xu and Xiang (2010) evaluated the performance of pharmaceutical retail enterprises based on principal component analysis and cluster analysis. Ma (2012) used factor analysis and DEA to evaluate the performance of retail enterprises from four aspects: profitability, operation ability, management level and social contribution. Du (2013) believes that retail enterprises have the problems of low profitability and unbalanced regional development. There is a positive correlation between enterprise scale and performance, and a negative correlation between capital structure and performance. $\mathrm{Wu}$ (2013) used factor entropy method to evaluate the performance of 59 listed retail enterprises, and found that the distribution of retail enterprises was uneven and the overall scale was small. Yang (2014) used the principle of Balanced Scorecard to evaluate the performance of retail enterprises. Fang (2017) believes that there is an inverted U-shaped relationship between the inventory management level and enterprise performance. Too high or too low inventory is not conducive to improving enterprise performance. Zhang (2019) used entropy value method to evaluate enterprise performance and put forward suggestions such as enriching enterprise formats and improving asset efficiency. Wang (2017) investigated the impact of capital structure, enterprise size, ownership structure and cost control on the performance of retail enterprises. Xue, $\mathrm{Wu}$ and Zhu (2019) evaluated retail enterprises with factor analysis method. On this basis, they proposed that the overall development of retail industry was good and the application of Internet technology should be strengthened. Domestic scholars mainly conduct empirical analysis on the retail industry, explore the development status and influencing factors.

Enterprise performance evaluation has formed a complete system, from focusing on financial indicators such as profitability to non-financial indicators such as environmental protection and growth potential. These indicators are the 
combination of long-term interests and short-term performance. Domestic scholars mainly use evaluation system for empirical analysis to explore the development status and influencing factors of retail enterprises.

This paper uses principal component analysis and factor analysis for performance evaluation. Firstly, the selection of indicators is relatively rich, including long-term and short-term performance factors, which can avoid the unilateral influence caused by extreme indicators and single indicators. Secondly, the empirical analysis using financial data has strong timeliness.

\section{Analysis of the Current Situation of Retail Enterprises}

\section{1. "Internet + Retail" Model, Combining Online and Offline}

The physical retail industry needs professional e-commerce operation talents and logistics distribution system to build online network by itself. Entry ecommerce industry is costly and time-consuming, which is not conducive to the play of economies of scale. In recent years, the growth rate of e-commerce has declined, facing the problem of developing new markets. The physical retail and e-commerce cooperation through the way of equity participation and strategic cooperation. Tencent and JD became shareholders of Yonghui Superstores, Alibaba became shareholders of Sanjiang Shopping, and launched strategic cooperation with Bailian. Physical retail and e-commerce to accelerate the pace of cooperation.

\subsection{Combination of New and Old Formats}

Department stores are the main business model in the traditional retail industry, while shopping centers and chain supermarkets are new business models. Department stores locate consumer groups according to income and class, and gather commodities with the same price positioning. Shopping centers draw profiles of consumer groups based on age, consumer preferences, psychology and other factors.

According to the portrait, the shopping center will aggregate the brands with the same positioning. Therefore, a shopping center is a consumption center integrating "shopping, entertainment, catering, tourism" and other functions.

The distribution of retail business forms is quite different. Among the 76 retail listed enterprises in 2015, there were about 57 enterprises with department stores and shopping centers as their main business forms. According to the "2017-2018 China Department Store Retail Development Report", more than $80 \%$ department stores surveyed were involved in other formats. Bailian, for example, focuses on department stores, shopping malls and discount stores; department stores and self-operated supermarkets are the main business forms in Chong Qing department stores. Convenience stores, as a new form of business, are developing rapidly. According to the CCFA, the convenience store boom index rose from 63.8 to 68.07 in 2019. In the development model, enterprises have also been making attempts, such as Rainbow Digital Commercial opened un- 
manned convenience stores. The retail industry is characterized by the combination of new and old forms of business.

\subsection{Carry out Chain Operation to Form Regional Competitive Advantage}

Most retail enterprises conduct chain operation around the country or region, and allocate main resources to key areas to form regional competitive advantages. For example, Maoye takes Shenzhen as the center, and extends to Wuxi, Chongqing, Chengdu and other central cities. Laiyifen is mainly based in Jiangsu, Zhejiang and Shanghai; Wangfujing mainly operates in the Beijing, Tianjin and Hebei; Dashang mainly in the northeast, across the northeast and southwest. Focusing on specific regions and expanding to the country can not only achieve the advantages of economies of scale, but also reduce the barriers to entry by taking advantage of the brand advantage.

\section{Empirical Analysis of Comprehensive Performance Evaluation}

Considering the availability of data and the continuity of operation, this paper selects listed retail enterprises with continuous operation from 2016 to 2018 and no major data missing. This paper uses factor analysis method to evaluate the performance of 44 retail enterprises from 2016 to 2018. In consideration of the advantages of principal component analysis and factor analysis, the average values of 44 retail enterprises from 2016 to 2018 are analyzed by principal component analysis. Performance evaluation comprehensively considers the profit level, development potential, capital structure and operation efficiency of enterprise assets.

\subsection{Selection of Indicators}

Index selection is shown in Table 1.

\subsection{Data Processing}

In this paper, 44 retail companies with continuous operation from 2016 to 2018 are selected, following the principles of: 1) excluding ST enterprises and 2) excluding enterprises with major data missing. Data source: CSMAR.

Table 1. Indicators.

\begin{tabular}{|c|c|c|c|}
\hline classification & secondary indicators & classification & secondary indicators \\
\hline \multirow{3}{*}{ Solvency } & Current ratio (CR) & \multirow{3}{*}{ Development } & Capital accumulation ratio (CAR) \\
\hline & Quick ratio $(\mathrm{QR})$ & & Growth rate of fixed assets (GRF) \\
\hline & Asset-liability ratio (ALR) & & Growth rate of total assets (GRA) \\
\hline \multirow{4}{*}{ Profitability } & Return on assets (ROA) & \multirow{4}{*}{$\begin{array}{c}\text { Operating } \\
\text { capacity }\end{array}$} & \\
\hline & Net profit margin on & & Accounts receivable turnover (ART \\
\hline & total assets (NPA) & & Total asset turnover (TAT) \\
\hline & Return on equity (R0E) & & \\
\hline
\end{tabular}


Asset-liability ratio is a moderate indicator, and the appropriate value $\mathrm{K}$ is 0.5 . The asset-liability ratio is positive according to $M=1 \div|\mathrm{Mi}-\mathrm{k}|$, that is, $\mathrm{M}$ is the replacement index of $\mathrm{Mi}$.

\subsection{Data Verification}

Factor analysis and principal component analysis cannot be used for dimensionality reduction when the original variables are unrelated. KMO is used to test the partial correlation of data. According to Table 2, the more KMO value is greater than 0.5 , it meets the conditions for factor analysis.

Bartlett Sphericity Test: The probability value from the table is 0 , which is lower than the significance level of 0.05 . It can be considered that there is a strong correlation between the original variables. The test results show that the data meet the requirements of factor analysis.

\subsection{Extraction of Principal Components}

According to Table 3, there are 4 principal components whose characteristic root is greater than 1 . The cumulative variance contribution rate of each year from 2016 to 2018 is all higher than $70 \%$, indicating that the extracted factors can explain the original variables well.

\subsection{Communality}

When the communality is greater than 0.4 , the original variable can be better explained by the common factor. According to Table 4, it is appropriate to use factor analysis method and principal component analysis method to evaluate the performance of enterprises.

Table 2. KMO and Bartlett test.

\begin{tabular}{lccccc}
\hline \multicolumn{2}{c}{ KMO and Bartlett's Test } & $2016-2018$ & 2016 & 2017 & 2018 \\
\cline { 1 - 4 } Kaiser-Meyer-Olkin Measure of Sampling Adequacy. & 0.547 & 0.652 & 0.608 & 0.602 \\
\hline \multicolumn{2}{c}{ Approx. Chi-Square } & 384.818 & 315.959 & 509.461 & 295.437 \\
Bartlett's Test of Sphericity & df & 66 & 66 & 66 & 66 \\
& Sig. & 0.000 & 0 & 0 & 0 \\
\hline
\end{tabular}

Table 3. Eigenvalue and variance contributions.

\begin{tabular}{|c|c|c|c|c|c|c|c|c|c|c|c|c|}
\hline \multirow[b]{2}{*}{ Component } & \multicolumn{2}{|c|}{ 2016-2018 } & \multicolumn{3}{|c|}{2018} & \multicolumn{3}{|c|}{2017} & \multicolumn{4}{|c|}{2016} \\
\hline & Total & $\begin{array}{c}\% \text { of } \\
\text { Variance }\end{array}$ & $\begin{array}{c}\text { Cumulative } \\
\%\end{array}$ & Total & $\begin{array}{c}\% \text { of } \\
\text { Variance }\end{array}$ & $\begin{array}{c}\text { Cumulative } \\
\%\end{array}$ & Total & $\begin{array}{c}\% \text { of } \\
\text { Variance }\end{array}$ & $\begin{array}{c}\text { Cumulative } \\
\%\end{array}$ & Total & $\begin{array}{c}\% \text { of } \\
\text { Variance }\end{array}$ & $\begin{array}{c}\text { Cumulative } \\
\%\end{array}$ \\
\hline 1 & 3.158 & 26.316 & 26.316 & 2.956 & 24.63 & 24.63 & 3.563 & 29.689 & 29.689 & 3.075 & 25.625 & 25.625 \\
\hline 2 & 2.913 & 24.274 & 50.59 & 2.868 & 23.902 & 48.531 & 3.024 & 25.196 & 54.885 & 2.28 & 19 & 44.625 \\
\hline 3 & 1.787 & 14.893 & 65.483 & 1.728 & 14.4 & 62.931 & 1.388 & 11.564 & 66.449 & 1.918 & 15.981 & 60.605 \\
\hline 4 & 1.048 & 8.736 & 74.219 & 1.055 & 8.788 & 71.72 & 1.162 & 9.685 & 76.134 & 1.463 & 12.191 & 72.796 \\
\hline
\end{tabular}


Table 4. Variance ratio.

\begin{tabular}{ccccccccc}
\hline \multirow{2}{*}{ index } & \multicolumn{2}{c}{$2016-2018$} & \multicolumn{2}{c}{2018} & \multicolumn{2}{c}{2017} & \multicolumn{2}{c}{2016} \\
\cline { 2 - 8 } & initial & extract & initial & extract & initial & extract & initial & extract \\
\hline ALR & 1 & 0.683 & 1 & 0.663 & 1 & 0.603 & 1 & 0.55 \\
CR & 1 & 0.847 & 1 & 0.871 & 1 & 0.81 & 1 & 0.767 \\
QR & 1 & 0.802 & 1 & 0.856 & 1 & 0.798 & 1 & 0.758 \\
ART & 1 & 0.384 & 1 & 0.813 & 1 & 0.607 & 1 & 0.212 \\
WCT & 1 & 0.742 & 1 & 0.209 & 1 & 0.625 & 1 & 0.782 \\
AT & 1 & 0.47 & 1 & 0.44 & 1 & 0.612 & 1 & 0.615 \\
ROA & 1 & 0.96 & 1 & 0.923 & 1 & 0.962 & 1 & 0.948 \\
NPA & 1 & 0.98 & 1 & 0.936 & 1 & 0.971 & 1 & 0.915 \\
RE & 1 & 0.903 & 1 & 0.834 & 1 & 0.963 & 1 & 0.898 \\
CAR & 1 & 0.805 & 1 & 0.831 & 1 & 0.751 & 1 & 0.83 \\
GRF & 1 & 0.442 & 1 & 0.364 & 1 & 0.768 & 1 & 0.637 \\
GRA & 1 & 0.888 & 1 & 0.865 & 1 & 0.666 & 1 & 0.823 \\
\hline
\end{tabular}

\subsection{Factor Naming}

According to Table 5, it is named according to the variables explained by the factors. Taking three years of average data as an example, factor 1 has a large load in the rate of return on assets, net interest rate on total assets and return on equity, which is named as profitability. Factor 2 has a large load on asset-liability ratio, quick ratio and current ratio, which is named as solvency. Factor 3 has a large load in the growth rate of fixed assets, capital accumulation rate and total assets growth rate, which is named as development capacity. Factor 4 has a large load in working capital turnover, total assets turnover and accounts receivable turnover are named as operating capacity. The same goes for 2018, 2017 and 2016.

\subsection{Calculate Factor Scores}

Take the principal component analysis from 2016 to 2018 as an example, according to the factor scoring coefficient matrix, the factor scoring function can be obtained as follows:

$$
\begin{aligned}
F_{1}= & 0.150 X_{1}+0.300 X_{2}+0.224 X_{3}-0.145 X_{4}-0.179 X_{5}-0.205 X_{6} \\
& +0.487 X_{7}+0.486 X_{8}+0.401 X_{9}+0.209 X_{10}+0.107 X_{11}+0.230 X_{12}
\end{aligned}
$$

$F_{2}$ to $F_{4}$ are calculated in the same way. For the sake of space, only the top 10 and bottom 10 companies are shown in Table 6 .

\subsection{Comprehensive Score of the Enterprise}

The variance contribution rate of common factors is used as the weight to calculate the comprehensive score of enterprises. For the sake of space, only the top 10 and bottom 10 companies are shown in Table 7.

$$
F=26.316 \% F_{1}+24.274 \% F_{2}+14.893 \% F_{3}+8.736 \% F_{4}
$$


Table 5. Factor.

\begin{tabular}{ccccccccccccccccc}
\hline & \multicolumn{1}{c}{$2016-2018$} & \multicolumn{1}{c}{2018} & \multicolumn{1}{c}{2017} \\
\cline { 2 - 4 } & 1 & 2 & 3 & 4 & 1 & 2 & 3 & 4 & 1 & 2 & 3 & 4 & 1 & 2 & 3 & 4 \\
\hline ALR & 0.267 & 0.737 & -0.12 & 0.233 & 0.811 & 0.037 & -0.063 & -0.004 & -0.231 & 0.673 & -0.185 & 0.251 & 0.323 & 0.639 & -0.008 & -0.192 \\
CR & 0.534 & 0.726 & 0.049 & 0.178 & 0.906 & 0.206 & -0.082 & -0.036 & 0.01 & 0.883 & -0.096 & 0.145 & 0.418 & 0.682 & 0.252 & -0.251 \\
QR & 0.398 & 0.78 & -0.09 & 0.165 & 0.901 & 0.182 & -0.088 & 0.052 & -0.111 & 0.874 & -0.145 & 0.025 & 0.372 & 0.768 & 0.071 & -0.158 \\
ART & -0.258 & 0.081 & -0.173 & -0.53 & 0.016 & -0.06 & 0.033 & 0.899 & -0.134 & -0.008 & 0.028 & -0.767 & -0.157 & -0.003 & -0.413 & -0.132 \\
WCT & -0.316 & -0.315 & 0.163 & 0.718 & -0.329 & 0.099 & -0.174 & -0.247 & -0.143 & -0.592 & -0.373 & 0.339 & -0.216 & 0.05 & 0.226 & 0.826 \\
AT & -0.364 & -0.503 & -0.028 & 0.288 & -0.623 & 0.194 & 0.03 & 0.112 & -0.087 & -0.652 & -0.411 & 0.103 & 0.078 & -0.361 & -0.155 & 0.674 \\
ROA & 0.866 & -0.355 & -0.287 & 0.045 & 0.096 & 0.955 & -0.037 & -0.024 & 0.978 & -0.066 & -0.036 & 0.013 & 0.903 & 0.342 & 0.022 & -0.123 \\
NPA & 0.864 & -0.368 & -0.313 & 0.021 & 0.185 & 0.949 & -0.021 & 0.017 & 0.983 & -0.067 & -0.025 & -0.001 & 0.885 & 0.35 & 0.031 & -0.096 \\
RE & 0.713 & -0.593 & -0.207 & -0.016 & -0.112 & 0.898 & 0.118 & -0.037 & 0.965 & -0.163 & 0.038 & 0.054 & 0.947 & -0.034 & 0.009 & 0.008 \\
CAR & 0.371 & -0.338 & 0.741 & 0.057 & 0.027 & 0.026 & 0.904 & 0.111 & 0.764 & 0.221 & 0.201 & 0.28 & -0.151 & 0.019 & 0.89 & 0.122 \\
GRF & 0.19 & 0.362 & 0.524 & -0.026 & 0.282 & -0.347 & 0.141 & -0.381 & -0.017 & -0.226 & 0.846 & 0.009 & 0.25 & -0.665 & 0.253 & -0.26 \\
GRA & 0.407 & -0.128 & 0.811 & -0.221 & -0.177 & 0.019 & 0.908 & -0.096 & 0.115 & 0.341 & 0.504 & 0.531 & -0.001 & -0.002 & 0.863 & -0.278 \\
\hline
\end{tabular}

Table 6. Factor score.

\begin{tabular}{|c|c|c|c|c|c|c|c|c|c|c|}
\hline \multirow[b]{2}{*}{ enterprise } & \multicolumn{2}{|c|}{ Profitability } & \multicolumn{2}{|c|}{ Solvency } & \multicolumn{2}{|c|}{ Development } & \multicolumn{2}{|c|}{ Operation } & \multicolumn{2}{|c|}{ Comprehensive } \\
\hline & score & ranking & score & ranking & score & ranking & score & Ranking & score & ranking \\
\hline Sanfo Outdoor & 2.32 & 5 & 4.68 & 2 & 3.31 & 1 & 0.38 & 9 & 2.27 & 1 \\
\hline Leysen Jewellery Inc. & 4.04 & 1 & 2.35 & 5 & -0.13 & 22 & 1.02 & 4 & 1.7 & 2 \\
\hline Shanghai Join Buy & 2.93 & 3 & 3.5 & 3 & -2.05 & 44 & 0.94 & 5 & 1.4 & 3 \\
\hline Xujiahui & 3.3 & 2 & 2.86 & 4 & -1.92 & 43 & 1.26 & 2 & 1.39 & 4 \\
\hline Global Top & 2.19 & 6 & -1.35 & 39 & 3.15 & 2 & -0.45 & 34 & 0.68 & 5 \\
\hline Yifeng Pharmacy & 1.81 & 7 & -0.51 & 27 & 2.01 & 5 & -0.49 & 36 & 0.61 & 6 \\
\hline Neptunus Bioengineering & 0.98 & 10 & -0.42 & 25 & 2.75 & 4 & -0.46 & 35 & 0.52 & 7 \\
\hline Baida Group & 0.64 & 13 & 1.83 & 6 & -1.03 & 34 & 0.21 & 16 & 0.48 & 8 \\
\hline CCOOP Group & 0.6 & 14 & -0.35 & 22 & 2.77 & 3 & -0.84 & 41 & 0.41 & 9 \\
\hline New World & 1.04 & 8 & 0.72 & 7 & -0.61 & 28 & 0.02 & 20 & 0.36 & 10 \\
\hline Grandbuy & -0.69 & 33 & -0.58 & 30 & -1.12 & 36 & 0.34 & 10 & -0.46 & 35 \\
\hline GIFORE & -1.57 & 42 & 0.1 & 14 & -1.15 & 38 & 0.83 & 6 & -0.49 & 36 \\
\hline Kai Kai Industry & -0.95 & 37 & -0.37 & 23 & -0.86 & 30 & -0.4 & 32 & -0.5 & 37 \\
\hline Hefei Department Store & -0.9 & 35 & -0.85 & 33 & -0.34 & 26 & -0.22 & 28 & -0.51 & 38 \\
\hline Huilong & -1.3 & 41 & -0.73 & 32 & -0.31 & 25 & 0.23 & 14 & -0.54 & 39 \\
\hline Dashang & -0.35 & 26 & -1.35 & 40 & -1.02 & 33 & 0.01 & 21 & -0.57 & 40 \\
\hline Grand Orient & -0.61 & 30 & -1.51 & 41 & -1.13 & 37 & 0.3 & 13 & -0.67 & 41 \\
\hline Hongqi Chain & -0.92 & 36 & -1.75 & 42 & -0.4 & 27 & 0.45 & 8 & -0.69 & 42 \\
\hline New Hua Du & -3.1 & 43 & -2.64 & 44 & 1.76 & 6 & 4.59 & 1 & -0.79 & 43 \\
\hline Zhongxing Commercial & -1.25 & 40 & 0.1 & 13 & -1.79 & 42 & -3.26 & 44 & -0.86 & 44 \\
\hline
\end{tabular}


Table 7. Comprehensive score.

\begin{tabular}{|c|c|c|c|c|c|c|c|c|}
\hline \multirow{2}{*}{ enterprise } & \multicolumn{2}{|c|}{$2016-2018$} & \multicolumn{2}{|c|}{2018} & \multicolumn{2}{|c|}{2017} & \multicolumn{2}{|c|}{2016} \\
\hline & score & ranking & score & ranking & score & ranking & score & ranking \\
\hline Sanfo Outdoor & 2.27 & 1 & -0.32 & 31 & 1.44 & 1 & 0.95 & 4 \\
\hline Leysen Jewellery Inc & 1.70 & 2 & 1.12 & 3 & 0.87 & 3 & 1.2 & 1 \\
\hline Shanghai Join Buy & 1.40 & 3 & 1.18 & 2 & 0.66 & 5 & 0.83 & 6 \\
\hline Xujiahui & 1.39 & 4 & 1.18 & 1 & 0.75 & 4 & 1.14 & 3 \\
\hline Global Top & 0.68 & 5 & 0.44 & 10 & 0.24 & 11 & 0.42 & 8 \\
\hline Yifeng Pharmacy & 0.61 & 6 & 0.46 & 9 & 0.27 & 10 & 0.46 & 7 \\
\hline Neptunus Bioengineering & 0.52 & 7 & 0 & 20 & 0.62 & 6 & 0.1 & 14 \\
\hline Baida Group & 0.48 & 8 & 0.5 & 8 & 0.17 & 14 & -0.06 & 20 \\
\hline CCOOP GROUP & 0.41 & 9 & -0.5 & 34 & 0.12 & 16 & -0.09 & 23 \\
\hline New World & 0.36 & 10 & 0.15 & 13 & 0.31 & 8 & -0.04 & 19 \\
\hline Grandbuy & -0.46 & 35 & -0.18 & 27 & -0.24 & 34 & -0.16 & 28 \\
\hline GIFORE & -0.49 & 36 & -0.39 & 33 & -0.66 & 42 & -0.13 & 27 \\
\hline Kai Kai Industry & -0.50 & 37 & -0.5 & 35 & -0.04 & 26 & -0.65 & 42 \\
\hline Hefei Department Store & -0.51 & 38 & -0.56 & 38 & -0.22 & 33 & -0.28 & 33 \\
\hline Huilong & -0.54 & 39 & -0.52 & 36 & -0.35 & 37 & -0.49 & 37 \\
\hline Dashang & -0.57 & 40 & 0 & 21 & -0.24 & 35 & -0.07 & 22 \\
\hline Grand Orient & -0.67 & 41 & -0.2 & 28 & -0.4 & 41 & -0.07 & 21 \\
\hline Hongqi Chain & -0.69 & 42 & 0.09 & 15 & -0.36 & 38 & -0.19 & 30 \\
\hline New Hua Du & -0.79 & 43 & -0.96 & 44 & -1.16 & 43 & 0.91 & 5 \\
\hline Zhongxing Commercial & -0.86 & 44 & 0.52 & 7 & -0.37 & 39 & -0.59 & 41 \\
\hline
\end{tabular}

\section{Analysis of the Results of Performance Evaluation}

The comprehensive score reflects solvency, turnover efficiency, profitability and development ability. The higher the score, the better the performance of the enterprise. Among them, Leysen Jewellery ranked No.2 in comprehensive score, and ranked top 3 every year. Shanghai Join Buy, Xujiahui and Yifeng Pharmacy all ranked top 10 in 2016-2018, indicating stable financial status and excellent performance. Huilong, Grand Orient, Hongqi Chain, New Hua Du, Zhongxing Commercial are ranked in the bottom $50 \%$, with poor overall performance.

According to the principal component analysis, the profitability of the enterprise is weak. Only 17 companies, less than $50 \%$, scored positive on profitability. Among them, 6 enterprises scored more than 2. Leysen Jewellery Inc ranked first in profitability with a score of 4.04, followed by a score of 3.30. The range of scores is 11.14. It indicates that there is a large gap in profitability among enterprises and the overall profitability level is insufficient. Xujiahui, Leysen Jewellery Inc and Shanghai Join Buy show strong profitability. NBZB ranked 16th in comprehensive score, but its profit score at the bottom of all enterprises. How- 
ever, the strong development capability and Solvency indicates that the enterprise has excellent liquidity and great development potential.

In the aspect of solvency, only 15 enterprises scored positive with 0 as the boundary, indicating that the solvency is insufficient. The score range is 9.08, ranking second among the four abilities. Xu Jiahui, Shanghai Join Buy, Leysen Jewellery Inc, NBZB and Sanfo Outdoor ranked in the top, showing excellent solvency. Huadong Medicine, Grand Orient, New Hua Du and Hongqi Chain ranked at the bottom, showing poor solvency among 44 enterprises. Combined with the turnover situation of enterprises, Hongqi Chain and New Hua Du are among the top 10 in terms of operation capacity, which can reduce the financial risk caused by the low solvency to a certain extent.

In terms of development ability, $43 \%$ of enterprises scored is positive. The score range is 5.36 , which is smaller in the four abilities, indicating that the difference in fixed asset investment such as plant and machinery is small.

In terms of operating capacity, 22 enterprises scored is positive, and 38 enterprises scored in the range of -1 to 1 , indicating that the difference between inventory and accounts receivable is narrow. Xujiahui, Wangfujing and New Hua Du showed strong operation ability. In the case of maintaining well relationship between customers and suppliers, adopting more strict credit conditions and improving inventory turnover can improve the efficiency of enterprise asset operation.

\section{Suggestions for Promoting the Development of Enterprises}

\subsection{Promote the Construction of Private Brand}

Only by meeting diversified and personalized needs, can enterprise improve customer stickiness and grasp pricing power. Improve profitability by improving the degree of product differentiation and providing effective supply. Firstly, enterprises need to make clear positioning and strengthen the construction of independent brands. At present, a number of department stores have launched their own brands, such as in time department store launched "Just Intime"; Tianhe department store establish "Teem Quality". The construction of independent brands requires market research and promotion, which is time-consuming and costly. Secondly, in the short term, enterprise can build a professional buyer team and establish a buyer shop to improve the differentiation level.

\subsection{Strengthen Supply Chain Management}

To improve the level of sales data and information sharing with suppliers; to integrate vertical mergers and acquisitions, so as to reduce transaction costs with suppliers; to select different supply chains according to the characteristics of products. For example, for products with unstable market demand, enterprise should mainly consider the speed and quality of supply; for products with stable market demand or low profit, enterprise should focus on controlling logistics 
and purchasing cost.

\section{Conclusion}

This paper uses principal component analysis to evaluate the performance of 44 retail listed companies from 2016 to 2018. It is found that there are great differences in profitability and solvency between enterprises. Strong turnover ability and development ability show that the retail industry has significant development potential. As a circulation link connecting production and final consumption, retail plays a role in stabilizing employment and ensuring reproduction. The development of massive data and artificial intelligence promotes the upgrading of retail industry. In the future, retail enterprises can improve profitability by mining customer needs, providing differentiated products and developing online and offline.

\section{Conflicts of Interest}

The author declares no conflicts of interest regarding the publication of this paper.

\section{References}

Chen, Z., Xu, J. P., \& Xiang, B. R. (2010). Evaluation of Business Quality of Pharmaceutical Distribution Enterprises Based on Principal Component Analysis and Cluster Analysis. Progress in Pharmaceutical Sciences, 34, 134-139.

Du, L. S. (2013). Research on the Factors Influencing the Performance of Chinese Retail Listed Companies. Master Thesis, Jinzhou: Bohai University.

Fang, L. (2017). The Relationship between Inventory Management Efficiency and Enterprise Performance in Retail Industry. Accounting Learning, No. 6, 163-164+168.

Kaplan, R. S., \& Norton, D. P. (1992). The Balanced Scorecardl-Measures That Dive Performance. Harvard Business Review, 70, 71-79.

Liao, X. J. (2007). Analysis on the Performance of Listed Retail Companies in China and Its Influencing Factors. Master Thesis, Nanjing: Nanjing Agricultural University,

Ma, L. (2012). Research on Performance Evaluation of Listed Retail Companies in China. Xi'an: Northwest University.

Wang, Z. (2017). Research on Financial Performance Evaluation and Influencing Factors of Listed Retail Companies in China. Master Thesis, Xi'an: Xi'an University of technology.

Wu, Q. (2013). Research on Performance Evaluation of Listed Companies Based on Factor Entropy Method. Master Thesis, Dalian: Dalian Jiaotong University.

Xue, Q. Y., Wu, Z. Y., \& Zhu, J. M. (2019). Comprehensive Evaluation of Financial Performance of New Retail Listed Companies Based on Factor Analysis. Journal of Science of Teachers' College and University, 39, 34-39.

Yang, S. (2014). Research on Performance Appraisal System of Retail Enterprises Based on Balanced Scorecard. Qingdao: Ocean University of China.

Zhang, Y. (2019). Research on Financial Performance Evaluation of Retail Listed Companies. Master Thesis, Jiangsu University of Science and Technology. 